\title{
The Education is Imparted by a Teacher
}

\author{
Dr. N.K. Singh
}

\begin{abstract}
Teacher make the student to understand how every body get influenced, moulded to confirm to a pattern, teacher perceptions must be to help students to be free of every kind of influence student need not to be told what is right action but to have capacity and drive to see the false and true that is teacher's concern is prematurity to cultivate their intelligence so that they can meet life with all its complexity with intelligently. Teacher sees this not as goal but as an immediate reality. Everybody knows that student get influenced by their parents, by their fellow students and by the world around them. Young people are easily influenced. They may rebel against it but consciously or unconsciously there is pressure and strain of this pressure. Teacher must be both introvert and extrovert, in the world of action and inwardly not be self-centered but turn owns eye and hearing to the subtitles of life. That is a teacher must be able to protect and at the same time cultivate generosity, be both the receiver and gives.
\end{abstract}

Key words: Teacher, Student, True-Education, Complexity, Personality and self.

\section{INTRODUCTION}

True education is imparted by a teacher or Guru since the down of civilization in every era. We have had the good fortune of having learned and skilled Gurus. The scriptures are the full of teachings and examples of Gurus like Vashistha, Vishwmitra, Vyas, Sandipan, Dronacharya etc. had these illustratious Gurus or educators been absent, could we think of personalities like Sri Ram, Sri Krishna and Arjun develop into what they have been? The answer would definitely be in negative. In modern era too we have a host of eminent Gurus and teacher like Swami Paramhans, Vivekanand, Osho, Mahes Yogi, Krishnamurti etc. Who have their own immutable style to teach the values of through spiritualism and modern educational techniques. Nowdays it's a general feeling that learning is encouraged through comparision, whereas the contrary is the fact. Comparision brings about trustations and merely encourages envy, which is called competition. Like other forms of a persuasion, comparision prevents learning and breads fear. Ambition also break fear, ambition, whether personal or identified with the collective is always anti social and destructive.

It is necessary to encourage the development of a good mind- a mind which is capable of dealing with many issues of life as a whole and which does not try to escape from them and so become self contradictory frustrated or cynical. It is essential for the mind to be aware of its own conditioning, its own motive and pursuits, since development of a good mind is one of our concerns, how one teaches becomes very important. There must be cultivation of totality of mind and not mere the giving of information. In the process of imparting knowledge, the educator has to invite discussion and encourage the students to inquire and to think independently.

Authority has no place in learning. The educator and the student are both learning through their special relationship with each other but this does not mean that the educator disregards the orderliness of the thoughts orderliness of thought is not brought about by discipline in the form of all explanatory statements of knowledge but it comes into being naturally when the educator understands that in cultivating intelligence their must be a sense of freedom. This does not mean freedom to do whatever one lives or to think in the spirit of mere contradiction. It is the freedom in which the student is being helped to be aware of his own urges and motives which are revealed to him through his daily thought and actions.

\section{METHODOLOGY}

Researcher has been used philosophical research accordance to Indian thinkers about teacher taught relationship. This is a qualitative type of research on importance of teacher's behaviour to develop the relation to achieve the goal of life for their students. Teacher approaches can develop the healthy society but need to improve in their behaviour with students.

\section{ANALYSIS \& DISCRIPTIONS}

Researcher point out that everyone is deeply involved in ones daily life as educators and human beings. One is first a human being and then educators, not the other way round. As a human being with a special profession of education, the teacher life is not only in the clas room but is involved with the whole outer world 
as well as inner struggles, ambition and relationship. Teacher is conditional as the student. Though there conditioning may vary, it is still a conditioning. If one accepts it as inevitable and abides by it, then one is conditioning other. There are many who accept this, trying to modify their limitations, but as an educator one is conceives the factility of wars and organized murders, a generation, which is concerned with global, internationalship without nationalistic isolation, a generation which is involved with truth. Surely this is the formation of true educator. The human consciousness is conditioned. Any thoughtfullman would accept this fact many of the person are not aware of this and perhaps neither are the educator. So become aware of ones conditioning and investigate whether it is possible to be free of its limitation is one of the function of teachers. So one has top go into the question what is to be aware to concentrate, to give total attention. It is very important to understand the meaning of all. Awareness implies sensitivity, to be sensitive to nature, to be aware of that poorman walking down the road, to be sensitive to that persons feeling, realtions to appealing and degrading poverty to be sensitive to the man who is next to other person. This sensitive has in it no choice, it is not critical. There is no judgemental evaluation. If one always through and always practice, then that very thought and practice skill sensitivity. One has to learn to observe sensitivity, to learn what sensitivity implies, one has to capture it rather than cultivate it.In the vary perception one is sensitive. There is no resistance in sensitivity. Sensitivity is to the immediate and limitless. Concentration is the process of resistance. Every educator knows what it mean to concentrate. The educator is concerned with suffering the brain with knowledge of various subjects so that the student will pass examinations and get a job. The students also hace this in his mind.

The educator and student are encouraging each other in the form of resistance, which is concentration. So one is building the capacity to resist, to exclude the gradually are becomes isolated. Concentration is the focusing of one's energy on the black board or a book avoiding destruction. So in this there is conflict, struggle and resistance. This resistance will inviatable, bring about the limitationof the brain which is our concentration. To perceive this whole movement with sensitivity is to move into a different area that is to be attentive. If we really grasp the significance of sensitivity of awareness, the limitation of concentration- not intellectually or verbally but actuality of such states: then one can ask what is to be attentive. Attention involve seeing and hearing. One hears not only with ears but also one is sensitive to tones. The voice, To the implication of words to hear without interference, to capture instantly the depth of sound. Sound plays an extraordinary path to our lives, the sound of thunder, a flute playing in the distance, the unheard sound of universe, the sound of silence, the sound of one's heart beat sound of a bird and the waterfall. The universe is filled with sound. This sound has its own silence; all living things involved in this sound of silence. To be attentive to hear this silence and move with it.

Seeing is very complex affair. One sees casually with one's eyes and swiftly passes by never seeing the details of a leaf, its form and structure, its colour, the variety of greens. To observe a cloud with all the light of the world in it, it to follow a stream chattering down the hill, to looks one's friend with the sensitivity in which there is no resistance, and to see oneself as one is without the shades of denial, to see the immensity of the universe, this is observation to see without the shadow of one self. Attention is the hearing and seeing and this attention has no limitation, no resistance so it is limitless. To attend implies this vast energy; it is not pinned down to a point. In this attention, there is no repetitive movement it is not mechanical. There is no question of how to maintain this attention and when one has learn this hearing and seeing, this attention can focus oneself on a page, a word. In this there is resistance, which is the activity of concentration.In alteration can not be refined into attention. To be aware of in attention is the ending of it, not that it becomes attentive. The ending has no continuity. The past modifying itself is the future a continuity of what has been and one find security in continuity not in ending. So attention has no quality of continuity. Anything that continues is mechanical. The becoming is mechanical and implies time. Attention has no quality of time. All this is tremendously complicated issue. One must gently deeply go into it.

Researcher pointed out the fact that one seems to think that education stops when one leaves school or college. One does not seem to treat the whole of human existence as the process of self education which is constant and perhaps never ending. So most of individuals limit education to a very short period and for the rest of one's life carry on in rather a muddle, learning only a few things that are absolutely necessary, falling into a routine \& of course there is always death waiting. This is really our life marriage, children, work passing pleasures, pain and death. If this is our real life, then one has to find the purpose of education and meaning in school and college as education. One has also inquired the purpose of teaching and teacher. It is a general understanding that a teacher having learnt so many subjects, in the form of student about them. This is very true that very few are in actual sense is a teacher. They are dedicated to helping the students in their studies but surely a teacher has far greater significance. 


\section{CONCLUSION}

It appears that very few teachers are aware of their great responsibility, not only to the parents but also in their relationship with students. If personality of teacher influences students then teacher became tyrant, discipline became conformity. The student imitate the teacher their ways, their gestures and so on. But teacher must not let students to follow teachers. Sensitivity implies being vulnerable. One is sensitive to one's reaction, to one's hurts, one's existence i.e. one is sensitive about oneself and in this vulnerable state, there is really self interest and therefore the capacity of being hurt. It is a form of resistance, which is essentially concentration on the self. The strength of vulnerability is not self centered. It is like the young spring leaf that can withstand strong winds and flourish.This vulnerability is incapable of being hurt, whatever the circumstances. Vulnerability is without center as the self. It has an extraordinary strength, vitality and beauty. Teacher has always with the students. Teachers are in this predicament that the primary and greatest importance is to bring about this intelligence in all the children $\&$ in the students for the whom one is responsible. Students have to face this world not as the specialized entity, which make the child incapable of meeting the world. All this implies the acquisition of knowledge \& careful discipline of knowledge. As long as the world is what it is, one has to work in a certain direction $\&$ child is occupied most of the time with that perhaps 8 or 10 hours a clay. Also child has to study and learn about the whole psychological world that has not been explored by anyone.Those who has explored somewhat tell what they have discovered, this become knowledge and student merely follows. This is not an accurate exploration into one self. The intent is not a goal to be achieved some time later. The intent is the ever present activity in which time is not involved at all.

Intent is for more important than achieve a goal on end. Intent is not just an intellectual \& ideological conclusion but also rather an active living present. It is wickie burning in the bowl of oil. It can not be extinguished, oil is not feed by any external influence or source. It has no cause and so the flame, the wick and the oil are ever in during. This is intent of dedicated teachers and it should be for parents and all humanity, for everybody is concerned. The vital flame of intent is to bring about good intelligent, extremely capable free human being. The future is everyone's responsibility, so this is individual problem. Individual's problem is to cultivate the comprehensive intelligence from which all other things flow. One can see this individual's mind, eye as a central factor, for no intelligent person in the sense one is using that word, would ever want to hurt another intentionally. Such a person would treat all humanity as one would trate oneself, without this terrible destructive division.

\section{REFERENCES}

[1] Beginings of learning, London \& New Delhi.

[2] Commentries on living, London $1^{\text {st }} 2^{\text {nd }}$ series, $1959,3^{\text {rd }}$ series 1961.

[3] Education and the significance of life, London 1962.

[4] Freedom from the known edited many Lutyens, London 1969.

[5] Reflection on the self: J. Krishnamurti.

[6] William Henderson, The teaching of krishnamurti, London 1979.

[7] Journal of the Krishnamurti school. 